DOI: $10.15679 / b j w r . v 4 i 1.48$

\title{
CURRENT ROLE, IMPORTANCE AND CHARACTERISTICS OF HUMAN DIMENSIONS IN WILDLIFE MANAGEMENT, A PRELIMINARY ASSESSMENT FROM EUROPEAN AND NORTH AMERICAN SCIENTIFIC JOURNALS
}

\author{
Lavadinović M. Vukan. ${ }^{1}$, Glikman A. Jenny ${ }^{2}$, Schraml Ulrich ${ }^{3}$
}

Summary: Human dimensions (HD) of wildlife management is a young field of enquiry which develops in several different directions and deals with various topics. Despite it is possible that popular research topics exist in HD studies, there is no proper research that identifies their role and importance. Besides, there is lack of knowledge on HD studies' worldwide distribution and research trends per different world regions.

The aim of this research was to provide knowledge on current role and characteristics of Human dimensions in wildlife management by analyzing four parameters: (1) proportion of HD studies, (2) current popular research topics in HD studies, (3) distribution of HD studies per world regions and (4) priorities in HD studies per world regions. For the purpose of this article, three journals such as The Journal of Wildlife Management (JWM), Human Dimensions of Wildlife (HDW) and European Journal of Wildlife Research (EJWR), which originate from North America and Europe, retrospectively, were analyzed for the period 2007-2012.

Results of this preliminary work show that the proportion of HD studies, in the JWM and EJWR journals, was low, only 2.6\%. Analysis of all three journals identified research topics like Large carnivores (15.07\%); Wildlife conservation (13.88\%); Wildlife management issues (13.88\%); and Human-wildlife conflict (13.16\%), as the most popular. A geographically biased manuscript distribution was evidenced as well as different popular research topics per world regions

Keywords: Human dimensions, wildlife, research priorities, distribution per regions

\section{Introduction}

The term Human dimensions (HD) was first introduced in 1970, despite Aldo Leopold long before stressed need for social studies in wildlife management (Schoenfeld, 1957; Bath, 1998; Manfredo et al., 1998). To date, course studies and research in HD are more widespread (Manfredo et al., 1998; Baxter et al., 1999; Heezik \& Seddon, 2005), but there is no proper research that identifies their role and relevance. The current status of HD studies is unknown, while its importance is subjectively estimated. Despite HD is a young scientific field of enquiry, it develops in several different directions and deals with various topics (Bath, 1998; Ericsson \& Heberlein, 2003; Heberlein et al., 2008; Slagle et al., 2013). Baxter et al., (1999) identified research priorities in wildlife management, Bath (1998) raised possibility of trends in HD. research, while Bonnet et al., (2002) detected that scientists tend to deal with popular topics in their research,

\footnotetext{
${ }^{1}$ Vukan Lavadonović MScEF assistant, Faculty of Forestry of University of Belgrade, Kneza Višeslava 1, 11030 Belgrade, Serbia

${ }^{2}$ Glikman A. Jenny, PhD Conservation Education, San Diego Zoo Global Institute for Conservation Research, 15600 San Pasqual Valley Road, Escondido, CA 92027, USA

${ }^{3}$ Schraml Ulrich Chair for Forest and Environmental policy, Albert Ludwig University of Freiburg, Tennenbacher Str. 4 (4.OG), D79106 Freiburg, Germany
} 
promoting scientific bias influenced by current societal interests, values (Wilson et al., 2007) or public concern (Martin-Lopez et al., 2010). Nowadays, HD studies are present in different forms worldwide (Ericsson \& Heberlein, 2003; Coleman et al., 2013; Asmyhr et al., 2013). According to Rahman \& Fukui (2003) and Soteriades et al., (2006) production of scientific manuscripts varies at the global level.

Such findings support assumption that research priorities and unequal scientific papers' output could also exist in HD studies. Results of Bonnet et al., (2002), Rahman \& Fukui (2003) and Soteriades et al., (2006) also raise a possibility that diversity in research priorities per different world regions could exist in HD studies.

Since it is not possible to provide adequate forecast of HD development without knowledge on the present situation, the aim of this paper is to identify current status of HD studies in wildlife management. For that purpose we identified four parameters: (1) proportion of HD studies in wildlife management, (2) current popular research topics in HD studies, (3) distribution of HD studies per world regions, and (4) priorities in HD studies per world regions.

\section{Conceptual model}

In order to better understand the status of HD studies, factors that influence the four identified parameters have to be analyzed. In this study five factors have been selected: (1) ecological/environmental characteristics; (2) human-wildlife conflict; (3) socio-economic features; (4) funds; and (5) wildlife management characteristics. Our opinion is that these factors diversely influence both each other and identified parameters that describe current status of HD studies (Figure 1).

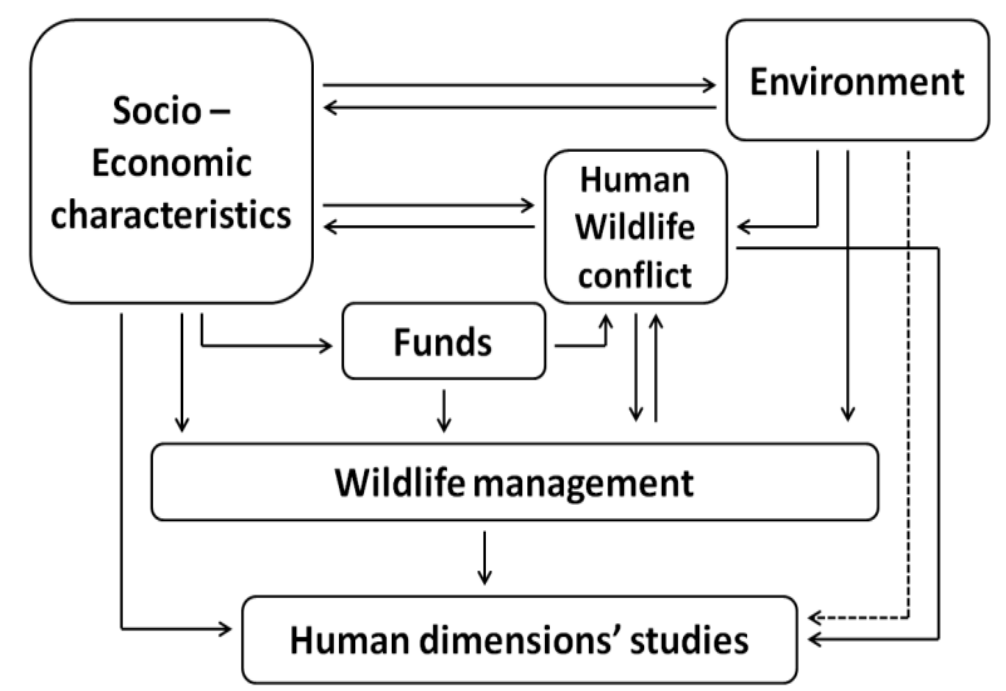

Figure 1. Factors that influence current status of Human dimensions’ studies

Natural resources abundance, even though is not prerequisite for economical development, it has a conspicuous role (le Billon, 2001). Besides, environment influences mold public values, attitudes and interests (de Groot et al., 2002), which are considered as part of Socio-economic parameter. Public attitudes, values and interests can vary from utilization to conservation measures, which retroactively shape environment. Interaction between these two parameters shape human-wildlife conflict, where ecological parameters influence conflict by natural characteristics and socio-economic ones the tolerance on it. It is in accordance with Teague (1979) citated in Jacobson \& Duff (1998): "Most wildlife management problems start out as biological problems, but eventually become people problems". Social response, according to the economic situation, is also present on human-wildlife conflict through funds directly used to overcome or resolve the conflict. These four factors influence wildlife management. Environmental features and humanwildlife conflict shape its characteristics and practices, while economical situation, human needs and preferences influence and modify wildlife management goals (Connover, 2001). All above mentioned factors in various forms influence and shape HD studies in scope, diversity and distribution. However, the 
most influential factor is within socio-economic characteristics - public interests and values (Wilson et al., 2007; Martin-Lopez et al., 2010), that affect HD studies both directly and indirectly through all other factors.

\section{Methods}

Research for this preliminary work was based on literature review of three journals: The Journal of Wildlife Management (JWM), European Journal of Wildlife Research (EJWR) and an international journal Human Dimensions of Wildlife (HDW) for a period 2007-2012. JWM and EJWR, were used to determinate the proportion of HD studies within wildlife management studies, since their content covers diverse topics in wildlife management and does not go beyond that framework. Therefore journals that have focus on classic biology or zoology were excluded. For the other three parameters HDW was also included. HDW was chosen due to its unique content, despite it misses impact factor. Nevertheless this lack does not affect its quality or importance among HD researchers.

In total, for the 6 year period, we analyzed 1,359 papers within 48 issues in the JWM, 572 papers within 32 issues in EJWR and 246 papers within 36 issues in HDW. In JWM we analyzed only scientific papers, both original and review papers, while in EJWR were analyzed all published manuscripts except category “Erratum”. In HDW Editorials, Errata, Corrigendum, Miscellaneous and Book reviews were not included in analysis. Manuscripts with research topics only focused on Anglers and Fishery were also excluded.

In order to identify HD current popular research topics all analyzed papers were selected according to their content, abstract or key words. In total 9 research topics were identified and used to classify manuscripts. Each manuscript could contain more than one research topic (see appendix).

Distribution of HD studies was evaluated per analyzed papers in different world regions, countries and federal states (for USA) in order to identify main contributors to the production of HD studies. Identification of world regions was based on methodology of Soteriades et al., (2006), although we used 8 regions: Asia, Africa, Oceania, Western Europe, Eastern Europe, Latin America and the Caribbean, the United States of America (USA) and Canada. Europe was divided according to former political ideology. Papers were classified according to the first author's home institution. Priorities in HD studies per world regions were identified according to crossed results from previous analyses.

\section{Results}

During analyzed period 2,177 manuscripts were published in the three analyzed journals, out of it 282 (12.95\%) accounted for HD studies. However, this figure was highly influenced with papers from the HDW. According to analysis of JWM and EJWR, the proportion of HD within wildlife management studies was very low. In JWM, out of 1,359 analyzed papers, 34 were HD studies, while in EJWR, out of 572 papers analyzed, 15 were HD studies. Although the JWM published 2.37 times more papers than the EJWR, the proportion of HD studies was almost the same, $2.50 \%$ and $2.62 \%$, respectively.

Overview of HD manuscripts detected differences in current popular research topics per analyzed journals. Nevertheless, only summarized results were taken in consideration to identify research priorities among HD scientists. Analysis of 282 HD manuscripts identified Large carnivores (15.07\%); Wildlife conservation (13.88\%); Wildlife management issues (13.88\%); Human-wildlife conflict (13.16\%); and Hunters (12.44\%) as the most popular research topics. These 5 topics, out of 9 , accounted for $68.43 \%$ of all published HD manuscripts in the three analyzed journals. Research topics such as Wildlife values was represented with $10.29 \%$ and Hunting with 9.57\%. Two last popular research topics were Non consumptive wildlife use $(4.78 \%)$ and Methods 
(4.55\%). Out of all analyzed HD manuscripts, 10 papers (2.39\%) did not fit any of previous research topics and as such remained indeterminate.

According to our analysis, USA was the dominant leader in published HD manuscripts with $70.21 \%$ of all papers. It was followed by Western Europe with $12.06 \%$ and Canada with $7.80 \%$ of all published papers. These three regions, out of 8, produced $90.07 \%$ (254 papers) of all HD published papers in the three analyzed journals. In total within 8 analyzed regions, 28 countries were identified (Table 1).

Table 1. Distribution of HD manuscripts from analyzed journals per countries of origin

\begin{tabular}{|c|c|c|c|c|c|c|c|}
\hline Country & N & Country & N & Country & N & Country & N \\
\hline USA & 198 & Japan & 4 & Uganda & 2 & Madagascar & 1 \\
\hline Canada & 22 & Finland & 3 & Cameroon & 1 & Nepal & 1 \\
\hline Netherlands & 8 & Poland & 3 & China & 1 & Panama & 1 \\
\hline UK & 6 & Austria & 2 & Denmark & 1 & $\begin{array}{c}\text { South } \\
\text { Africa }\end{array}$ & 1 \\
\hline Australia & 5 & Germany & 2 & Estonia & 1 & Switzerland & 1 \\
\hline Norway & 5 & Kenya & 2 & Greece & 1 & Tanzania & 1 \\
\hline Sweden & 5 & $\begin{array}{c}\text { New } \\
\text { Zeland }\end{array}$ & 2 & India & 1 & Thailand & 1 \\
\hline
\end{tabular}

Since the USA is a federation, we analyzed distribution of HD studies per states. According to analysis 37 out of 50 states (74\%) were involved, out of which leading states are Colorado (14.14\%), New York (10.10\%), Michigan (8.08\%), Wisconsin (6.06\%), Texas (5.56\%) and Minnesota (5.05\%). Other states are represented with less than 5\%, among which Ohio and Virginia, both with $4.55 \%$, are far more productive than the others. In total these 8 leading states accounted for $58.09 \%$ of the HD manuscripts from USA. In Western Europe the most productive countries were the Netherlands and United Kingdom (UK). Scandinavian countries (Norway, Sweden, Finland and Denmark), produced $41.18 \%$ of HD manuscripts from Western Europe.

Popular research topics in HD studies have been analyzed only for three leading regions - USA, Canada and Western Europe, since other had insufficient numbers of HD manuscripts. In USA the most popular research topic was Large carnivores (14.93\%) followed with Wildlife management issues (14.58\%) and Hunters (14.24\%). In Canada two research topics gathered same amount of HD manuscripts: Large carnivores (23.08\%) and Human - wildlife conflict (23.08\%) followed with research topics Wildlife management issues (12.82\%) and Wildlife conservation (12.82\%) which also gathered same amount of papers. Western Europe, as a region, had at first place two research topics with same amount of gathered papers $-15.56 \%$ : these research topics were Large carnivores and Hunting. They were followed with papers on Human - wildlife conflict (13.33\%) and Wildlife conservation (13.33). Manuscripts on Hunters gathered 11.11\%. However in the Netherlands 2/3 of papers were focused on Wildlife value orientations, in UK half of papers were focused on Wildlife conservation, while among Scandinavian countries researchers were focused on topics such as Large carnivores (25\%), Hunting (25\%) and Hunters (20\%).

\section{Discussion}

As preliminary research, this study has several limitations. Since it analyzed only scientific journals from North America and Europe, it is likely that it could influence findings and decrease actual contribution of different world regions in HD studies. Focus only on journals written in English 
could underestimate HD productivity in Europe (Glikman \& Frank, 2011). Therefore it is assumed that other world regions or countries have higher HD manuscript production in other journals or on their native languages, than one identified in this study. This study did not take in consideration potential change of the four studied parameters per time, which could identify and explain potential research trends among HD scientists for analyzed period. Also research priorities have not been analyzed for non-HD manuscripts in three journals, which could influence HD studies. However, these oversights do not influence evaluation of current HD status, but could be an interesting and valuable topic for future research. Despite possible bias, this study provides preliminary overview on importance of HD studies in wildlife management as well on other analyzed parameters of HD studies. Furthermore, this possible bias could only influence the ratio between regions' production, not their position in the list of the most productive world regions.

The proportion of Human dimensions studies in analyzed journals was on average 2.6\%. Due to the increase of offered HD courses at universities (Heezik \& Seddon, 2005), it was supposed that the number of HD manuscripts would follow its development. Except of Baxter et al., (1999) no other comparable study was identified, but despite differences it was observed that HD studies were significantly less represented than others. Although we agree that the HD component of wildlife management grows (Decker \& Enck, 1996; Jacobson \& Duff, 1998; Manfredo et al., 1998), it is still poorly represented in scientific manuscripts per analyzed wildlife management research journals.

Out of these top popular research topics, Large carnivores, Wildlife conservation and Humanwildlife conflict overlapped. Popularity of these topics was somehow expected due to specific role large carnivores have in conservation biology (Leader-Williams \& Dublin, 2000) and increased of their abundance (Swenson et al., 2000), but also due to more frequent human-wildlife conflict caused by large carnivores (Garrote et al., 2013). This finding was also in accordance with Glikman \& Frank, (2011). Human-wildlife conflict fits to HD aims, since it goes beyond biologists' expertise (Jacobson \& Duff, 1998). Popularity of Wildlife conservation topic is based on increased environmental awareness and as such is in accordance with findings of Baxter et al., (1999).

Unequal manuscript distribution is present, since the leading world regions in HD studies were USA, Canada, Western Europe and Oceania. These findings supported results from Soteriades et al., (2006), especially since USA is identified with 70\% of all analyzed manuscripts as leading region. Besides, HD studies originated in USA (Schoenfeld, 1957; Manfredo et al., 1998). Except Western Europe leading regions are part of English speaking countries, while in leading countries out of top 5 only the Netherlands is a non-speaking English country. These finds are in accordance with Tsai \&Wen, (2005) who stated that in scientific journals the major contribution was from English speaking countries. Actually out of 10 leading countries, all were English speaking or somehow linked with USA, mostly by direct cooperation with USA researchers.

Besides uneven manuscripts' distribution HD faced different regional research priorities. We implemented our conceptual model to explain research priorities on examples of Scandinavian region, the Netherlands and USA. The Scandinavian countries have high proportion of hunters in the population with an increasing trend (Kawata, 2011). They also have specific environmental properties, which are allowing population increase or recovery of large carnivores (Swenson et al., 2000). Except large carnivores initiate special conservation measures, they are linked with traditional and rising conflict with humans, habitat degradation or livestock depredation that form negative attitudes towards them (Garrote et al., 2013). They also evoke a fascination and represent flagship species in conservation biology (Leader-Williams \& Dublin, 2000) which makes them common research topic. Furthermore, they challenge HD scientists to address problems that go beyond biological sciences (Jacobson \& Duff, 1998). These mix of socio-economic and environmental parameters combined with human-wildlife conflict and specific wildlife management practices resulted with popular research topics in HD like Large carnivores, Hunting, Hunters and Human-wildlife conflict were. 
Netherlands is one of world's most densely populated country with high level of urbanization, which made it highly nature-friendly country where protective attitudes rise to cultural dominance (de Groot \& van den Born, 2002) and Dutch put efforts to protect values of wilderness (van den Berg \& Koole, 2006). Therefore, the public in the Netherlands hold very strong environmental values. In such circumstances the combination of modest environmental characteristics, due to high urbanization, specific public interests, and values influence HD studies through research priorities, and made Wildlife values the most popular HD topic.

In the USA wildlife management and conservation measures are financed from purchased hunting licences (Heberlein, 1991). Since the number of issued hunting licences directly influences wildlife protection, hunters have an important role in society (Organ \& Fritzell, 2000). The number of hunters in the USA is much higher than in Europe, around 7\% (Statistic brain, 2012). However, according to Heberlein (1991), hunters' numbers are decreasing and threaten financial support of wildlife conservation. Also the hunting is a human activity that raises many controversies (Shaw, 1977; Looker, 1994), and interests among HD researchers. In this case socio-economic parameter combined with wildlife management practices and funds directly influence HD studies' research priorities and placed Hunters as the second most popular research priority in the USA. Within USA this research topic was popular in Mid-West and South regions which have according to U.S. Fish and Wildlife Service and U.S. Census Bureau for 2012 the highest hunters' participation within the population.

\section{Conclusion}

Despite poor representation, we expect that the role of HD studies will become more widespread. The current importance of HD studies in wildlife management cannot respond to social challenges, which face wildlife managers and hunters. We are aware from personal experience that HD papers' production in several European countries is directly influenced by cooperation with North American scientists. Therefore the role of North American scientists in HD papers production is even more important. However that burden should not be carried out only by the USA and English speaking countries but also in appropriate form by every world region and country, since growing opportunity and exigency for HD in wildlife management exist.

\section{Acknowledgement}

This paper was realized as a part of the project TD 31041 financed by the Ministry of Education and Science of the Republic of Serbia within the framework Technological development for the period 2011-2014.

\section{REFERENCES}

1. Asmyhr, L., Willebrand, T., Hörnell-Willebrand, M. (2013) The optimal foraging theory, crowding and Swedish grouse hunters. European Journal of Wildlife Research 59(5), pp. 743-748.

2. Bath, A.J. (1998) The Role of Human Dimensions in Wildlife Resource Research in Wildlife Management. Ursus series 10, pp. 349-355.

3. Baxter, G.S., Hockings, M., Carter, R.W., Beeton, J.R.S. (1999) Trends in Wildlife Management and the Appropriateness of Australian University Training. Conservation Biology 13(4), pp. 842-849.

4. le Billon, P. (2001) The political ecology of war: natural resources and armed conflicts. Political Geography 20(5), pp. 561-584.

5. Bonnet, X., Shine, R., Lourdais, O. (2002) Taxonomic chauvinism. Trends in Ecology \& Evolution 17(1), pp.1-3. 
6. Coleman, T.H., Schwartz, C.C., Gunther, K.A., Creel, S. (2013) Grizzly bear and human interaction in Yellowstone National Park: An evaluation of bear management areas. The Journal of Wildlife Management 77(7), pp.1311-1320.

7. Conover, M.R. (2001) Resolving Human-Wildlife Conflicts: The Science of Wildlife Damage Management. Lewis publishers, CRC Press LLC, Boca Ratton, Florida, USA.

8. Decker, D.J., Enck, J.W. (1996) Human dimensions of wildlife management: Knowledge for agency survival in the 21st century. Human Dimensions of Wildlife 1(2), pp. 60-71.

9. Ericsson, G., Heberlein, T.A. (2003) Attitudes of hunters, locals, and the general public in Sweden now that the wolves are back. Conservation Biology 111(2), pp.149-159.

10. Garrote, G., Gil-Sánchez, J.M., Rojas, E., Ruiz, M., Bueno, J.F., de Lillo, S., Rodriguez-Siles, J., Martin, J.M., Pérez, J., García-Tardío, M., Valenzuela, G., Simón, M.A. (2013) Human-felid conflict as a further handicap to the conservation of the critically endangered Iberian lynx. The Journal of Wildlife Management 59(2), pp.287-290.

11. Glikman, J.A., Frank B (2011) Human Dimensions of Wildlife in Europe: The Italian way. Human Dimensions of Wildlife 16(5), pp. 368-377.

12. de Groot, R.S., Wilson, M.A., Boumans, R.M.J. (2002) A typology for the classification, description and valuation of ecosystem functions, goods and services. Ecological Economics 4(3), pp.393-408.

13. Heberlein, T.A. (1991) Changing Attitudes and Funding for Wildlife: Preserving the Sport Hunter. Wildlife Society Bulletin 19(4), pp. 528-534.

14. Heberlein, T.A., Serup, B., Ericsson, G. (2008) Female Hunting Participation in North America and Europe. Human Dimensions of Wildlife 13(6), pp. 443-458.

15. Heezik, Y.V., Seddon, P.J. (2005) Structure and Content of Graduate Wildlife Management and Conservation Biology Programs: an International Perspective. Conservation Biology 19(1), pp. 7-14.

16. Jacobson, S.K., Duff, M.D. (1998) Training Idiot Savants: The Lack of Human Dimensions in Conservation Biology. Conservation Biology 12(2), pp. 263-267.

17. Kawata, Y. (2011) Economic growth and trend changes in wildlife hunting. Acta Agriculturae Slovenica 97(2), pp.115-123.

18. Leader-Williams, N., Dublin, H.T. (2000) Charismatic megafauna as ‘flagship species'. In: Entwistle A, Dunstone N (2000) Priorities for the Conservation of Mammalian Diversity - Has the Panda had its day? Conservation Biology 3. Cambridge: University of Cambridge Press. Ch. 4.

19. Looker, C.A. (1994) The Colorado black bear hunting controversy: A case study of human dimensions in contemporary wildlife management. Ithaca: Human Dimensions Research Unit, Dept. of Natural Resources, Cornell University.

20. Manfredo, M.J., Decker, D.J., Duda, M.D. (1998) What is the Future for Human Dimensions of Wildlife. Transactions $63^{\text {rd }}$ North American Wildlife and Natural Resources Conference, pp.278-292.

21. Martín-López, B., Montes, C., Ramirez, L., Benayas, J. (2010) What drives policy decision-making related to species conservation? Conservation Biology 142(7), pp. 1370-1380.

22. Organ, J.F., Fritzell, E.K. (2000) Trends in consumptive recreation and the wildlife profession. Wildlife Society Bulletin 28(4), pp. 780-787.

23. Rahman, M., Fukui, T. (2003) Biomedical publication—global profile and trend. Public Health 117(4), pp. 274-280.

24. Shaw, W.W. (1977) A survey of hunting opponents. Wildlife Society Bulletin 5(1), pp. 19-24.

25. Schoenfeld, C.A. (1957) Public Relations Aspects of Wildlife Management. The Journal of Wildlife Management 21(1), pp. 70-74.

26. Slagle, K., Zajac, R., Bruskotter, J., Wilson, R., Prange, S. (2013) Building tolerance for bears: A communications experiment. The Journal of Wildlife Management 77(4), pp. 863-869.

27. Soteriades, E.S., Rosmarakis, E.S., Paraschakis, K., Falagas, M.E. (2006) Research contribution of different world regions in the top 50 biomedical journals (1995-2002). Faseb Journal 20(1), pp. 29-34.

28. Statistic brain. (2012) Hunting statistics. http://www.statisticbrain.com/hunting-statistics. Accessed 27 April 2013.

29. Swenson, J.E., Gerstl, N., Dahle, B., Zedrosser, A. (2000) Action Plan for the conservation of the Brown Bear (Ursus arctos) in Europe. Nature and environment 114. Council of Europe publishing.

30. Tsai, C.C., Wen, M.L. (2005) Research and trends in science education from 1998 to 2002: a content analysis of publication in selected journals. International Journal of Science Education 27(1), pp.3-14.

31. Van den Berg, A.E., Koole, S.L. (2006) New wilderness in the Netherlands: An investigation of visual preferences for nature development landscapes. Landscape and Urban Planning 78(4), pp. 362-372.

32. Wilson, J.R., Procheş, S., Braschler, B., Dixon, E.S., Richardson, D.M. (2007) The (bio)diversity of science reflects the interests of society. Frontiers In Ecology And The Environment 5, pp. 409-414. 


\section{Appendix}

List and description of Research topics identified in this study:

$\underline{1 . H u n t i n g}$-papers that analyze wildlife consumption and recreation through hunting activities or practices, and studies that explore or analyze hunting characteristics and factors that influence it. These papers deal with all forms of hunting. Since hunting is considered as shooting or using animals as whole or their body parts, this category includes also trapping and poaching as illegal hunting activity.

2. Hunters -papers that analyze the stakeholders' perspective, therefore that focus on hunters or other actors involved in hunting, their opinions, attitudes, motivation or behavior, as well their recruitment, retention or any other characteristics. Difference from pervious topic is that these papers are focused on persons.

3. Human-wildlife conflict -papers that study interaction between wild animals and people such as vehicle-animals collision, management in (sub) urban areas, conflict between land users and implementation of conservation measures. Although there are several types of human-wildlife conflict, we did not distinguish them. Human conflicts with large carnivores are excluded from this category (see category 5).

4. Wildlife conservation - papers that analyze well-being of animals and they are focused on wildlife protection and population recovery. However, this topic does not include research on large carnivores (see category 5).

5. Large carnivores - although papers grouped here could also fit other topics, they were separated in order to identify how popular this topic is among today's researchers. Therefore, all papers that deal with large carnivores in any context are grouped here. Under large carnivores are considered big animals from Ordo Carnivora that predate or are capable of predation on other mammals although they are omnivores.

6. Wildlife values -papers that analyze non-hunters' attitudes, emotions or opinions on wildlife management issues or practices in general as well on specific animal species.

7. Wildlife management issues - papers that analyze wildlife management characteristics, practices, measures, incomes or awareness. Wildlife management is considered as a process that tries to manipulate wildlife populations, habitats and people to meet requirements of sustainable development and societal goals. Papers that involve hunters, as well any hunting or conservation measures have been placed in other categories.

8. Non consumptive use -manuscripts that analyze recreation, tourism, bird-watching and other varieties of nonconsumptive use of wild animals.

$\underline{\text { 9. Methods }}$-papers that analyze different methods used by scientists in their research.

10. Indeterminate papers -manuscripts that could not fit any other research topic and were too few in number to be identified as separate topic. This group gathers introduction papers for special HD issues, perception of non-hunters groups about various issues in HD, characteristics of wildlife biologists or review on HD authors. In total this group gathered 10 papers.

Received: 15.09.2016.

Accepted: 14.011.2016.

Lavadinovic V., Glikman A. J., Schraml U. (2017). Current role, importance and characteristics of human dimensions in wildlife management, a preliminary assessment from European and North American scientific journals, Balkan Journal of Wildlife Research, 4(1), pp. 21-28. 